\title{
Factors predisposing to the development of progressive massive fibrosis in coal miners
}

\author{
D H SHENNAN,* J S WASHINGTON, D J THOMAS, J A DICK, $\dagger$ Y S KAPLAN, \\ AND J G BENNETT
}

From the National Coal Board Radiological Service, London SWI, UK

ABSTRACT Altogether 238759 miners employed by the National Coal Board were examined in the third of the Board's radiological surveys from 1969 to 1973 inclusive. Excluding those diagnosed as having progressive massive fibrosis (PMF) on that occasion, 210847 were in collieries still operating at the time of the fourth survey four to five years later; 132728 attended for radiography at the same colliery on the second occasion, and were used to study the attack rate of PMF. In all groups in the age range 35-54 and having category 2 simple pneumoconiosis (SPN) or less, $80 \%$ or more had a second radiograph. It was found that the probability of developing PMF increased sharply with rising category of SPN; however, half the cases occurred in men having SPN categories 0 or 1 , who were in the majority. Current coalface work had no significant effect on the attack rate. Age increased the attack rate of PMF within each major SPN category $(0,1,2$, and 3$)$, especially the higher categories. All or part of this effect may have been due to the fact that SPN in younger men with categories 1 and 2 tends to lie in the lower range within these categories. Similarly, a lower distribution of SPN within each category associated with a low overall local prevalence may account wholly or in part for the great difference between the attack rates of PMF supervening on each category of SPN in Scotland and South Wales. The rank (quality) of coal mined had no effect on the attack rate.

Progressive massive fibrosis (PMF) is the most disabling form of coal workers' pneumoconiosis ${ }^{2}$ and the only form that shortens life considerably. ${ }^{34}$ Once started it tends to increase fairly rapidly 5 and may continue to increase despite removal from the dust hazard. ${ }^{6}$ For these reasons an important aim of dust control in collieries is the prevention of PMF. In recent years the problem of how this may best be achieved has had attention from groups appointed by the Government ${ }^{7}$ and by the National Union of Mineworkers, ${ }^{8}$ but both studies were somewhat hampered by a lack of information. To find out more

Requests for reprints to: Dr J A Dick, National Coal Board Radiological Centre, Golden Smithies Lane, Wath-on-Dearne, South Yorkshire S63 7EW.

* Now tuberculosis physician, Swaziland.

†Deputy Director of Medical Services.

$\ddagger$ Now senior clinical medical officer, Rotherham Area Health Authority.

Received 18 September 1980

Accepted 22 December 1980 about what sort of miner is likely to develop PMF, we have looked at the results of routine radiographs taken by the National Coal Board (NCB), who have carried out periodic radiographic (PXR) surveys since 1959 . We have analysed the colliery population examined at the third survey round and then re- $x$ rayed at the same colliery in the fourth round, four to five years later.

The factors that we have been able to study in this way are the category of simple pneumoconiosis (SPN) on the first occasion, current exposure to face work, age, and rank of coal mined. The first three of these have been looked at previously, but with smaller numbers of miners.

Category of SPN-The higher the category of SPN, the more likely is it that PMF will supervene. ${ }^{9-11}$

Current face work-PMF may progress even if there is no further exposure to dust. ${ }^{612}$ There is uncertainty, however, as to whether current exposure to dusty conditions increases the chance of developing 
PMF in a miner with any given category of SPN. Dust studies referred to by McLintock et al ${ }^{11}$ indicated that exposure to respirable dust (2-5 micron particles) was directly implicated. There was no support for the suggestion that quartz dust is a factor in the aetiology.

Age-There is no doubt that older miners are much more prone to develop PMF, but it is less clear whether this effect is secondary to the higher prevalence of SPN in older men or whether age has an additive, independent effect. ${ }^{10}{ }^{11}$ McLintock et al ${ }^{11}$ looked at the attack rate at ages within minor ILO categories of SPN and concluded that age, as such, might be of some importance.

Coal rank-Bennett et al ${ }^{13}$ have shown a relationship between coal rank (quality) and the prevalence of SPN.

In addition to the influences which we were in a position to assess it is possible that immunological status is important in determining the occurrence of PMF. ${ }^{14-16}$

\section{Method}

Altogether 238759 miners were $x$-rayed in the third PXR survey round, which covered all NCB collieries in Britain between 1969 and 1973. These represented $91.6 \%$ of the defined colliery population.

We analysed the $x$-ray data in the third and fourth survey rounds of all miners who were read as being free from PMF in the third round and who were re- $x$-rayed in the fourth round (four to five years later) at the same colliery. Men at collieries that had closed by the fourth round are therefore excluded. The eligible population from the third round was 210847 . The number of these re- $x$-rayed at the same colliery in the fourth round was 132728 . The remainder had retired, left, or moved to a different colliery between the two surveys, or failed to turn up for radiography at the fourth round. They included many men aged over 55 and many younger men who showed no pneumoconiosis at the third round survey.

The rank (quality) of coal mined at a colliery was determined as described by Bennett et al. ${ }^{13}$

\section{Results}

\section{VALIDITY OF STUDY}

\section{Reliability of readings of SPN}

There is considerable variation between readers in general in their assessment of SPN category. To minimise this variation, the NCB radiological
Table 1 Comparison of prevalence of category 1 or more pneumoconiosis in faceworkers, by $x$-ray centre, obtained by individual readers, with that obtained by all readers combined in the epidemiological assessments

\begin{tabular}{|c|c|c|}
\hline \multirow[t]{2}{*}{ Centre } & \multicolumn{2}{|c|}{$\%$ Prevalence of category 1 or more } \\
\hline & Individual reading & Epidemiological reading \\
\hline 1 & 3.9 & $2 \cdot 8$ \\
\hline 2 & $10 \cdot 4$ & $10 \cdot 4$ \\
\hline 3 & $8 \cdot 8$ & $10 \cdot 9$ \\
\hline 4 & $7 \cdot 0$ & 9.8 \\
\hline 5 & $5 \cdot 4$ & 7.0 \\
\hline 6 & $23 \cdot 4$ & $19 \cdot 2$ \\
\hline All centres & $9 \cdot 1$ & 9.9 \\
\hline
\end{tabular}

medical officers are calibrated against each other annually by means of film-reading checks, and they also meet at intervals to read films together. In the 1971 check on 350 films taken at random from all areas, the five readers (one reader covered centres 1 and 2; centre 7 was not represented) varied from $22 \%$ to $30 \%$ in the proportion of films read as showing category 1 SPN or higher. Table 1 compares the prevalence of category 1 or more in face workers by $x$-ray centre, obtained from the individual clinical readings used for this study, with the corresponding prevalence derived from the epidemiological readings, to which all the readers contributed. (The collieries surveyed by centre 7 (the Pneumoconiosis Field Research (PFR) at the Institute of Occupational Medicine, Edinburgh), which are located in all areas, are included among those of the other centres for the purpose of epidemiological reading.) It will be seen that the variation in prevalence between centres obtained by individual readers agrees fairly well with that found by the consensus of all readers.

\section{Realiability of readings of $P M F$}

NCB readers identify PMF if they see a shadow greater than $1 \mathrm{~cm}$ in diameter that they believe to be due to pneumoconiosis. In clinical reading, the results of which were used for this study, the decision is being made in the interests of the subject and carries the weight of clinical responsibility, especially if the man has not yet been certified and the reader must decide whether to advise him to apply to the pneumoconiosis medical panel. Two main sources of error arise in diagnosing PMF:

(a) Other conditions can produce similar shadows. If the reader is not reasonably satisfied that PMF is present he will refer the man for investigation at a chest clinic in the first instance, and not enter the result of the radiograph as PMF. In this way some men having PMF are excluded from the results, and conversely some not having PMF may be entered as having it. The results of the present study, however, show a well-pronounced gradient in the attack rate 
of PMF in miners read as having different categories of SPN, ranging from $0.06 \%$ (category 0 ) to $18 \%$ (category 3). This is an indication that PMF is not being widely confused with other lesions, even allowing for the possibility that knowledge of the SPN category may influence the diagnosis.

(b) The coalescence of shadows of SPN into PMF is often a gradual process, and readers may disagree as to the precise moment at which they aggregate into a shadow of more than $1 \mathrm{~cm}$. Overall there was $60 \%$ agreement with the pneumoconiosis medical panels as to the presence or otherwise of PMF.

Four per cent of men given a diagnosis of PMF on the first occasion were read as having reverted to no-PMF the second time. In the great majority, therefore, the diagnosis of PMF was still considered correct four years later.

\section{Completeness of follow-up}

In each of the 35-44 and 45-54 age groups the proportion re- $x$-rayed was $80 \%$ or more. This level was maintained for men who were originally read as having categories 1 and 2, indicating that men did not leave the industry (though they may have left face work) because of these degrees of pneumoconiosis. For those with category 3 the follow-up rate fell to about $70 \%$, so possibly some of these left because they had this category. We may expect that a small proportion of men developing PMF during this period had it discovered elsewhere and thereupon left the industry. Such men would, however, be much more likely to remain with the colliery and change to a non-dusty occupation.

For men aged 55 or over the follow-up rate was only $21 \%$, which is too low for the derivation of reliable results. There was a relatively low re- $x$-ray rate in men aged 15-34, but this does not affect the results, as no new case of PMF was diagnosed among them.

We conclude that reliable PMF attack rates can be drawn for the miners aged 35-54, and the main analysis will be confined to them.

Table 2 PMF attack rate per 100 men by $x$-ray centre and category of SPN at first $x$-ray: men aged 35-54

\begin{tabular}{|c|c|c|c|c|}
\hline \multirow[t]{2}{*}{ Centre } & \multicolumn{4}{|c|}{ Category } \\
\hline & 0 & 1 & 2 & 3 \\
\hline 1 & 0.01 & 0.5 & - & - \\
\hline 2 & 0.05 & 1.5 & 7 & 11 \\
\hline 3 & 0.07 & 0.7 & 3 & 6 \\
\hline 4 & 0.02 & $1 \cdot 9$ & 11 & 25 \\
\hline 5 & 0.06 & $2 \cdot 1$ & 9 & 14 \\
\hline 6 & $0 \cdot 16$ & $2 \cdot 0$ & 9 & 24 \\
\hline 7 & 0.06 & $1 \cdot 1$ & 9 & 15 \\
\hline All centres & 0.06 & $1 \cdot 5$ & 7 & 18 \\
\hline
\end{tabular}

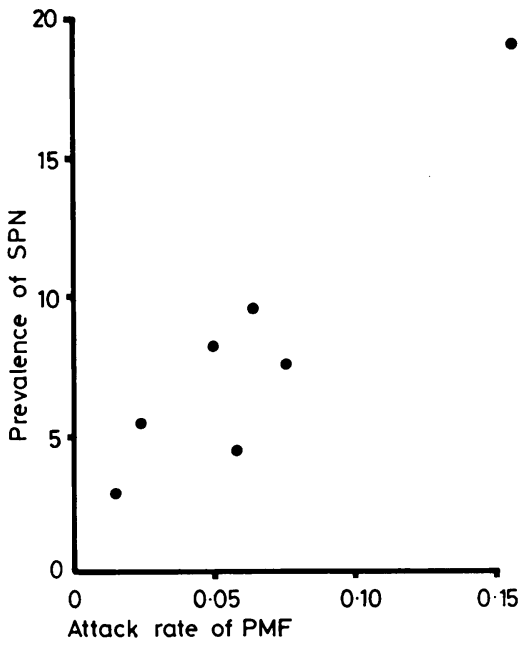

Fig 1 Prevalence of $S P N$, all categories, and subsequent attack rate of PMF on category 0 at ages $35-54$, by $x$-ray centres.

\section{Comparison of results from different $x$-ray centres}

Mean age differed little between centres, varying from $39 \cdot 7$ to $41 \cdot 1$. Table 2 shows the PMF attack rate by initial category of SPN and $x$-ray centre. There is a clear and steep gradient with ascending category, shared by all seven centres.

The attack rate of PMF in men previously read as category 0 shows a close relationship to the local prevalence of category 1 or more (fig 1 ).

\section{PMF DEVELOPING BY CATEGORY AND AGE}

Within each age group there was a sharp rise in the attack rate of PMF with increasing category of SPN, as shown in table 3 . For the whole $35-54$ age range the rate increased from $0.06 \%$ in category 0 to $18 \%$ in category 3 (fig 2).

Within this age range PMF incidence increased with rising age, most obviously in men who started with category 2; fig 3 illustrates this. If the considerably less reliable figures for men aged 55 or over are included the trend is seen to extend into this group also.

DEVELOPMENT OF PMF "B", FROM SPN

From Table 3 it can be seen that as with all categories of PMF taken together, the incidence of PMF category B read after a film four to five years earlier, which had been regarded as showing SPN only, is closely related to the initial category of SPN read.

There was no case in which category $\mathrm{C}$ was read on the second occasion when no PMF had been recorded the first time. 
Table 3 PMF attack rate by category of SPN and age

\begin{tabular}{|c|c|c|c|c|c|c|}
\hline \multirow[t]{2}{*}{ Age } & & \multicolumn{4}{|c|}{ Category of SPN at first $x$-ray } & \multirow[t]{2}{*}{ All cats } \\
\hline & & 0 & $I$ & 2 & 3 & \\
\hline $35-44$ & $\begin{array}{l}\text { Total } \\
\text { PMF } \\
\% \text { PMF }\end{array}$ & $\begin{array}{r}33586 \\
6 \\
0.02\end{array}$ & $\begin{array}{r}1255 \\
13 \\
1.0\end{array}$ & $\begin{array}{l}212 \\
8 \\
3 \cdot 8\end{array}$ & $\begin{array}{r}8 \\
1 \\
13\end{array}$ & $\begin{array}{l}35061 \\
28 \\
0.08\end{array}$ \\
\hline $45-49$ & $\begin{array}{l}\text { Total } \\
\text { PMF } \\
\% \text { PMF }\end{array}$ & $\begin{array}{r}24317 \\
23 \\
0.09\end{array}$ & $\begin{array}{r}2217 \\
36 \\
1.6\end{array}$ & $\begin{array}{c}570 \\
36 \\
6 \cdot 3\end{array}$ & $\begin{array}{r}46 \\
8 \\
17\end{array}$ & $\begin{array}{c}27150 \\
103 \\
0.38\end{array}$ \\
\hline $50-54$ & $\begin{array}{l}\text { Total } \\
\text { PMF } \\
\% \text { PMF }\end{array}$ & $\begin{array}{r}20538 \\
17 \\
0.08\end{array}$ & $\begin{array}{r}2712 \\
43 \\
1.6\end{array}$ & $\begin{array}{c}807 \\
68 \\
8 \cdot 4\end{array}$ & $\begin{array}{l}77 \\
15 \\
19\end{array}$ & $\begin{array}{r}24134 \\
143 \\
0.59\end{array}$ \\
\hline $35-54$ & $\begin{array}{l}\text { Total } \\
\text { PMF } \\
\% \text { PMF } \\
\text { PMF “B”, } \\
\% \text { PMF "B" }\end{array}$ & $\begin{array}{c}78441 \\
46 \\
0.06 \\
15 \\
0.02\end{array}$ & $\begin{array}{c}6184 \\
92 \\
1 \cdot 5 \\
12 \\
0 \cdot 2\end{array}$ & $\begin{array}{c}1589 \\
112 \\
7 \cdot 0 \\
18 \\
1 \cdot 1\end{array}$ & $\begin{array}{r}131 \\
24 \\
18 \\
6 \\
5\end{array}$ & $\begin{array}{c}86345 \\
274 \\
0.32 \\
51 \\
0.06\end{array}$ \\
\hline$\geqslant 55$ & $\begin{array}{l}\text { Total } \\
\text { PMF } \\
\% \text { PMF }\end{array}$ & $\begin{array}{r}8885 \\
7 \\
0.08\end{array}$ & $\begin{array}{r}1497 \\
33 \\
2 \cdot 2\end{array}$ & $\begin{array}{c}518 \\
50 \\
9 \cdot 7\end{array}$ & $\begin{array}{r}30 \\
8 \\
27\end{array}$ & $\begin{array}{c}10930 \\
98 \\
0.90\end{array}$ \\
\hline
\end{tabular}

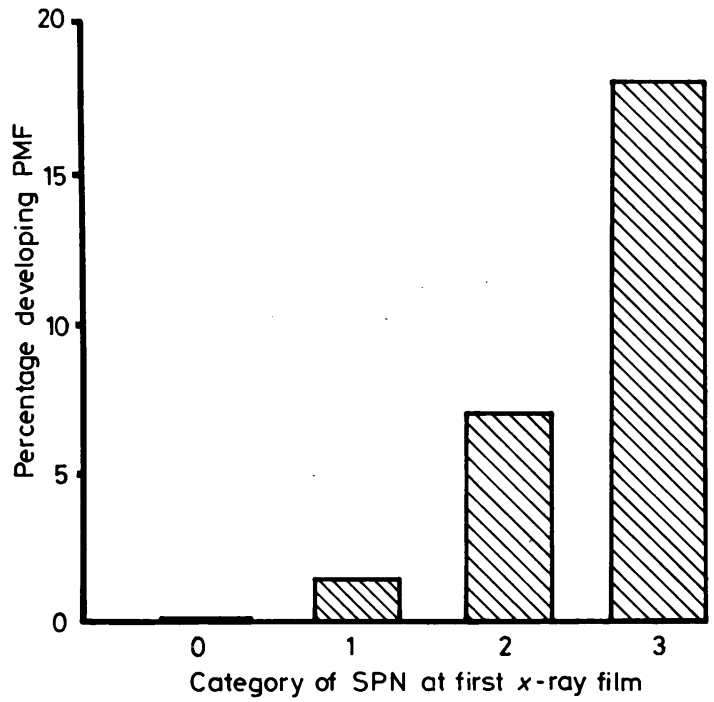

Fig 2 PMF attack rate by category of SPN in miners aged 35-54.

EFFECT OF CONTINUING EXPOSURE TO FACE WORK

Comparison of the SPN readings on the first and second occasions confirms the generally held belief that face work produces more SPN than work away from the coalface. The increase between the two surveys was $2.23 \%$ for face workers compared with $1.21 \%$ for non-face workers. Miners who are face workers for a long period can therefore be expected to have, on average, a higher category of SPN and

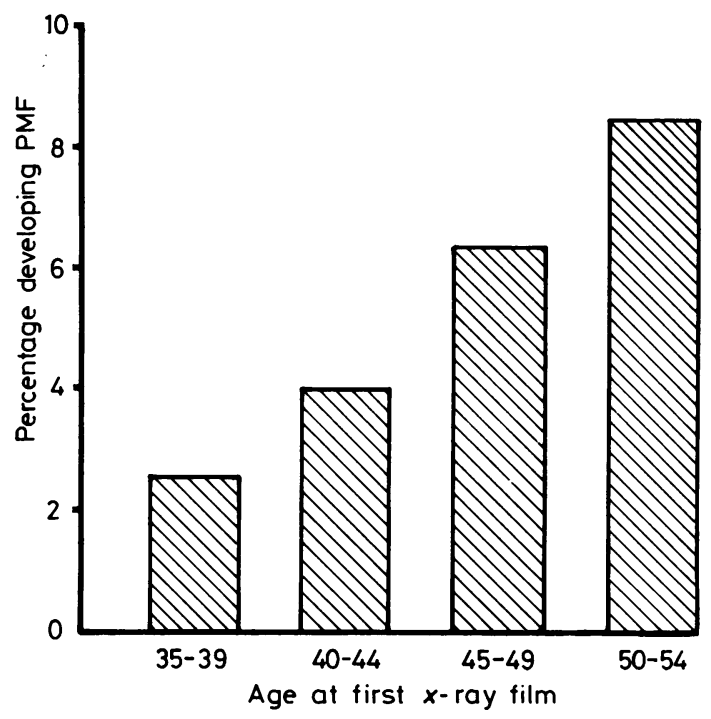

Fig 3 PMF attack rate on SPN category 2, by age.

hence a greater liability to develop PMF. We looked into the question of whether PMF is more likely to develop in men who are currently being exposed to the greater concentrations of dust found at the coal face.

The proportions of first-survey face workers and non-face workers who were read as having PMF on the second occasion were almost identical $(0.31 \%$ and $0.32 \%$ respectively), and this held good within each initial category of SPN (table 4). 
Table 4 PMF attack rate per 100 men by category of SPN, age, and whether working at the coal face on the first occasion

\begin{tabular}{|c|c|c|c|c|c|c|c|c|}
\hline \multirow[t]{3}{*}{ Category } & \multicolumn{8}{|l|}{ Age } \\
\hline & \multicolumn{2}{|l|}{$35-44$} & \multicolumn{2}{|l|}{$45-49$} & \multicolumn{2}{|l|}{$50-54$} & \multicolumn{2}{|c|}{ All ages 35-54 } \\
\hline & Face & Not face & Face & Not face & Face & Not face & Face & Not face \\
\hline $\begin{array}{l}0 \\
1 \\
2 \\
3 \\
\text { All cats }\end{array}$ & $\begin{array}{l}0.01 \\
1 \cdot 3 \\
3 \cdot 4 \\
- \\
0 \cdot 10\end{array}$ & $\begin{array}{l}0.02 \\
0.5 \\
4 \cdot 3 \\
- \\
0.06\end{array}$ & $\begin{array}{c}0.09 \\
1.8 \\
6.6 \\
21 \\
0.45\end{array}$ & $\begin{array}{c}0 \cdot 10 \\
1 \cdot 4 \\
6 \cdot 1 \\
15 \\
0 \cdot 32\end{array}$ & $\begin{array}{c}0.09 \\
1 \cdot 3 \\
7 \cdot 3 \\
17 \\
0.55\end{array}$ & $\begin{array}{c}0.08 \\
1.8 \\
9 \cdot 1 \\
20 \\
0.62\end{array}$ & $\begin{array}{l}0.05 \\
1.5 \\
6 \cdot 3 \\
20 \\
0.31\end{array}$ & $\begin{array}{c}0.06 \\
1.5 \\
7.6 \\
18 \\
0.32\end{array}$ \\
\hline
\end{tabular}

From age 50 upwards the non-face workers, apart from those whose initial category was 0 , had a slightly higher attack rate of PMF than the face workers. It could therefore be argued that men who were face workers at the time of the first $x$-ray were likely to develop more SPN during the period between the two surveys, and as a result show more PMF when $x$-rayed the second time. The PMF attack rates by SPN category were therefore recalculated on the basis of the SPN category found on the second occasion for the original face and non-face groups. The pattern of PMF attacks was unchanged, indicating that this factor was not important.

\section{EFFECT OF COAL RANK}

Of the 132728 miners, 113341 were in collieries whose coal rank could be defined according to the criteria given by Bennett $e t$ al. ${ }^{13}$ No pattern relating the attack rate of PMF to the rank of coal mined could be identified in any $x$-ray centre's area.

\section{Discussion}

\section{CATEGORY OF SPN}

By far the most important factor predisposing to an attack of PMF was the initial category of SPN, confirming the findings of other studies; the continuation of this trend into category 3 is shown convincingly (table 3 ). McLintock et al ${ }^{11}$ showed the same trend on a large retrospectively selected population of face workers using simultaneous readings; the number of miners available to Cochrane $^{10}$ was not sufficient to do this.

The pre-eminence of the category of SPN in the causation of PMF underlines the fact that the prevention of PMF depends on the prevention of SPN, which in turn depends on minimising exposure to respirable dust.

The results support the statement by Craw et al ${ }^{8}$ that the presence of category 2 or more SPN greatly increases the danger that PMF will supervene. Looked at the other way round, however, table 3 shows that of the 274 cases of PMF arising in the
35-54 age group, 138 had last been read as having category 0 or 1 , because of the much larger numbers of miners having these categories. If therefore SPN of categories 2 and 3 were totally prevented, only half of the problem of PMF would have been solved; the statement by Craw et al that "PMF usually develops on a background of category 2 or 3 " is not supported. Cochrane's ${ }^{10}$ opinion that the aim should be to prevent miners from reaching the stage of category 2 SPN should be reviewed in the light of this.

\section{LOCAL PREVALENCE OF SPN}

The finding, illustrated by fig 1 , that the attack rate of PMF in miners previously read as having category 0 is related to the local prevalence of SPN category 1 or more, is important in considering the relationship of prevalence (and also of age) to the attack rate of PMF. A moment's reflection shows that even within a single category, the average level of SPN is likely to be lower in a low prevalence area than in a high prevalence area. This can be illustrated by comparing centre 1 (Scotland), where a few of the most severely affected just reach category 2, with centre 6 (South Wales), where the proportion of miners with category $\mathbf{2}$ or more is 29 times as high. Similarly, during the decades of dust exposure that usually precede the radiological appearance of category 1 SPN, there must be a build-up in the lungs of a state that can be described as preradiological pneumoconiosis. There will be an even wider variation in the degree of this preradiological state with varying prevalence than in the average level of SPN within one of the categories 1,2 , or 3 . This phenomenon goes some way towards accounting for the otherwise unexplained difference in the PMF attack rate between Scotland and South Wales that is mentioned by McLintock et al. ${ }^{11}$

Melville $e t a^{12}$ tabulate data for cumulative lifelong dust exposures in men whose subsequent $x$-ray films were examined by three readers for the new development of PMF. Nine, read previously as category 0 and found currently by at least two of the 
readers to have developed PMF, had a mean cumulative exposure of $319 \mathrm{ghr} / \mathrm{m}^{3}$, whereas the average cumulative exposure for all men aged 60 or over was only $219 \mathrm{ghr} / \mathrm{m}^{3}$. This indicates that those miners who develop PMF on category 0 are the ones with high cumulative exposures to dust.

\section{CURRENT DUST EXPOSURE}

Men working at the coal face when $x$-rayed on the first occasion did not develop significantly more PMF than those away from the face. Face workers aged 50 and over who were read as having SPN of categories 1 to 3 at the start actually fared slightly better than non-face workers in this age group. A possible explanation is a constitutional difference between the two groups. Those who remain at the face may, for instance, be more robust, and if immunological factors are indeed important they may be better equipped in this respect to resist the development of PMF.

\section{AGE}

The finding (table 3, fig 3 ) that increasing age was of importance, independently of SPN category, confirms the impression gained by McLintock et al. ${ }^{11}$ Cochrane $^{10}$ did not find age significant, probably because of the small numbers available. Our findings run counter to the statement by Craw et al ${ }^{8}$ that "younger men with SPN have the greatest risk of developing PMF."

Possibly the age gradient is partly or wholly due to a lower average radiological SPN level within each category carried by younger men; this would be represented by a predominance in older men of the higher ILO subcategories of each main category 0,1 , 2 , and 3, and of the lower subcategories in younger men. The mechanism postulated is the same as that producing more PMF on a single SPN category in high-prevalence areas, discussed above.

We are grateful to Dr R M Archibald, director of medical services, NCB, for encouragement and for permission to publish this paper. Drs J Burns, W M Prentice, D A Scarisbrick, and D Walker were among the film-readers in the third and fourth PXR rounds. We thank Mrs E Baxter and Dr P O Pern for valuable criticism.

\section{References}

${ }^{1}$ Hart P D'Arcy, Aslett EA. Chronic pulmonary disease in South Wales coalminers. I Medical studies. B Medical survey. London: MRC, 1942. (Medical Research Council Special Report Series No 243.)

${ }^{2}$ Rogan JM, Ashford JR, Chapman PJ, Duffield DP, Fay JWJ, Rae S. Pneumoconiosis and respiratory symptoms in miners at eight collieries. Br Med J $1961 ; \mathrm{i}: 1337-42$.

${ }^{3}$ Cochrane AL, Carpenter RG, Moore F, Thomas J. The mortality of miners and ex-miners in the Rhondda Fach. Br J Ind Med 1964;21:38-45.

+ Cochrane AL. Relation between radiographic categories of coal workers' pneumoconiosis and expectation of life. Br Med J 1973;ii:532-4.

${ }^{5}$ Cochrane AL, Moore F, Thomas J. The radiographic progression of progressive massive fibrosis. Tubercle $1961 ; 42: 72-7$.

${ }^{6}$ Cochrane AL, Carpenter RG. Factors influencing the radiological progression rate of progressive massive fibrosis. Br J Ind Med 1956;13:177-83.

7 Industrial Injuries Advisory Council. Pneumoconiosis and byssinosis. London: HMSO, 1973. (Cmnd 5443.)

${ }^{8}$ Craw J, Davies D, Hart JT, Jones S, Kennedy MCS. Coalworkers' pneumoconiosis, emphysema and bronchitis: a report to the National Union of Mineworkers. London: Macdermott \& Chant, 1978.

${ }^{9}$ Cochrane $\mathrm{AL}$, Miall WE. Factors influencing the radiological attack rate of progressive massive fibrosis. $\mathrm{Br}$ Med J 1956; : : 1193-9.

${ }^{10}$ Cochrane $\mathrm{AL}$. The attack rate of progressive massive fibrosis. Br J Ind Med 1962;19:52-64.

${ }^{11}$ McLintock JS, Rae S, Jacobsen M. The attack rate of progressive massive fibrosis in British coal miners. In: Walton WH, ed. Inhaled particles III. Old Woking: Unwin Bros, 1971 :933-52.

${ }^{12}$ Melville AWT, Paris I, Hurley JF, Soutar CA. Pneumoconiosis, lung function and exposure to airborne dust: epidemiological research to compare responses of working coalminers with responses of ex-miners. Edinburgh: Institute of Occupational Medicine, 1979.

${ }^{13}$ Bennett JG, Dick JA, Kaplan YS, et al. The relationship between coal rank and the prevalence of pneumoconiosis. Br J Ind Med 1979;36:206-10.

${ }^{14}$ Soutar CA, Turner-Warwick M, Parkes W. Circulating antinuclear antibody and rheumatoid factor in coal pneumoconiosis. Br Med J 1974; iii:145-7.

${ }^{15}$ Boyd JE, Robertson MD, Davies JMG. The examination of serum samples from coal miners for the presence of auto antibodies that might be involved in the development of progressive massive fibrosis. National Coal Board Medical Service Broadsheet 1980;19, Nos 1-2:34-7.

${ }^{16}$ Miall WE, Caplan A, Cochrane AL, Kilpatrick GS, Oldham PA. An epidemiological study of rheumatoid arthritis associated with characteristic chest $x$-ray appearances in coal workers. Br Med J 1953;ii:1231-6. 